\title{
The Influence of Pre-Milling on the Microstructural Evolution During Mechanical Alloying of a $\mathrm{Fe}_{50} \mathrm{Cu}_{50}$ Alloy.
}

\author{
F.M. Lucas ${ }^{1}$, B. Trindade ${ }^{1}$, B.F.O. Costa ${ }^{2}$, G. Le Caër ${ }^{3}$ \\ ${ }^{1}$ ICEMS, Departamento de Engenharia Mecânica, Universidade de Coimbra, \\ Pinhal de Marrocos, P-3030 Coimbra - Portugal \\ ${ }^{2}$ Departamento de Física, Universidade de Coimbra, P-3000 Coimbra - Portugal \\ ${ }^{3}$ GMCM, CNRS UMR 6626, Université de Rennes-I, Campus de Beaulieu, Bât. 11A, Avenue du \\ Général Leclerc, F-35042 Rennes Cedex - France
}

Keywords: Fe-Cu, Solid solution, Premilling, Mechanical alloying, Mössbauer spectroscopy.

\begin{abstract}
Fe}_{50} \mathrm{Cu}_{50}$ solid solutions have been obtained by two different mechanical alloying routes, i.e. from $\mathrm{Fe}-\mathrm{Cu}$ powders with and without premilling. These two alloying processes were studied and compared at two rotation speeds of a planetary ball-mill, namely $200 \mathrm{rpm}$ and $300 \mathrm{rpm}$. The microstructural evolution of the ball-milled powders as a function of milling time was monitored using electron probe microanalysis, X-ray diffraction, scanning electron microscopy and Mössbauer spectroscopy. In both processing routes, a broad distribution of different local environments of the iron atoms was observed in the Mössbauer spectra of the fcc-FeCu phase. Mössbauer spectra show further that a fcc non magnetic Fe-rich phase is formed transiently besides the bcc-Fe phase. The $\mathrm{Fe}-\mathrm{Cu}$ reactions are slowed down when premilled powders are used as starting powders but similar fcc solid solutions are formed during milling. As expected, the mechanical alloying process is faster at $300 \mathrm{rpm}$ but the final results are similar using $200 \mathrm{rpm}$ or $300 \mathrm{rpm}$.
\end{abstract}

\section{Introduction}

Far from equilibrium synthesis processes have been used to produce materials with non-equilibrium structures, e.g. amorphous alloys, supersaturated solid solutions, metastable crystalline phases and nanocrystalline materials, with good mechanical and physical properties suitable for high performance materials. For instance, a giant magnetoresistance effect has been measured in $\mathrm{Fe}-\mathrm{Cu}$ alloys for different iron concentrations [1]. According to the $\mathrm{Fe}-\mathrm{Cu}$ phase diagram, $\mathrm{Fe}$ and $\mathrm{Cu}$ are immiscible at room temperature. However, alloying of $\mathrm{Fe}$ and $\mathrm{Cu}$ is known to be feasible by highenergy ball-milling [see for instance [2-10]). During mechanical milling, iron and copper powders quickly agglomerate and are repeatedly flattened and welded by the colliding balls. This gives rise to a lamellar structure which breaks down by further co-deformation into $\mathrm{Fe}$ needle-shaped particules via multiple necking to rupture [6]. This process induces the formation of nanosized grains in which $\mathrm{Fe}$ atoms are dissolved in the $\mathrm{Cu}$ matrix ( $\mathrm{fcc} \mathrm{Cu}(\mathrm{Fe})$ solid solution). Single-phase structures have been obtained by MA in a broad concentration range of the $\mathrm{Fe}-\mathrm{Cu}$ system, e.g. fcc $\mathrm{Cu}(\mathrm{Fe})$ solid solution for iron contents lower than 45 at.\% and bcc $\mathrm{Fe}(\mathrm{Cu})$ solid solution for iron contents higher than 55 at.\% [3]. In between, the two phases, $\mathrm{Cu}(\mathrm{Fe})+\mathrm{Fe}(\mathrm{Cu})$ co-exist $[2,8]$. However, some results of Mössbauer and of atom probe investigations indicate that these solid solutions are chemically heterogeneous on a nanometer scale $[2,5,6,8,9]$. Further, supersaturated solid solutions formed deep inside a miscibility gap through rapid quenching or solid state routes may have decomposition features on the scale of a few nanometers as shown recently for sputtered fcc Ag-Cu solid solutions [10] or for mechanically alloyed $\mathrm{Fe}_{30} \mathrm{Cr}_{70}$ alloys (the same conclusion holds for milled as-cast $\mathrm{Fe}_{30} \mathrm{Cr}_{70}$ alloys) [11]. Similar results on heterogeneous alloys are reported 
by other authors on mechanically alloyed $\mathrm{Fe}-\mathrm{Cu}$ mixtures with and without subsequent annealing $[2,5-8]$. In a recent work on nanocrystalline $\mathrm{Fe}_{\mathrm{y}} \mathrm{Cu}_{1-\mathrm{y}}(0.141 \leq \mathrm{y} \leq 0.450)$ alloys produced by ball milling [6], Fernandez et al. used small-angle x-ray scattering technique to conclude that the synthesised alloys are heterogeneous on a nanometer scale since composition fluctuations were detected inside nanocrystalline grains. Wanderka et al [5] investigated the microstructure and composition on the nanometer scale of mechanically alloyed $\mathrm{Cu}_{50} \mathrm{Fe}_{50}$ solid solution with a tomographic atom probe. They concluded that samples contain nanometer-sized regions with strongly varying composition. By contrast, the existence of homogeneous fcc $\mathrm{Cu}(\mathrm{Fe})$ solid solution with a random distribution of iron and copper atoms in the lattice was reported by Huang [12] on $\mathrm{Fe}-\mathrm{Cu}$ alloys milled at low energy. The bimodal nature of hyperfine magnetic field distributions found in $\mathrm{Fe}_{50} \mathrm{Cu}_{50}$ prepared by high-energy ball-milling and further ball-milled at low energy [7] was explained either by a nonrandom distribution of $\mathrm{Fe}$ atoms in the alloy, by variations in the magnetic moments of $\mathrm{Fe}$ atoms depending on their local environments, or by composition fluctuations of the order of 1 at.\%. It was not possible to distinguish between these causes.

Although MA has long been used for the preparation of $\mathrm{Fe}-\mathrm{Cu}$ alloys, little attention has so far been paid to the effect of the characteristics of the starting powders on the microstructural evolution during milling. In fact, premilling of the initial powders, which modifies some of their mechanical characteristics and, consequently, the transfer of energy from colliding balls to entrapped powder particles [13], might change the way $\mathrm{Fe}$ and $\mathrm{Cu}$ are mixed at a nanometric scale. The highest solubility of magnesium in titanium was for instance achieved when both elemental powders were made brittle by premilling before mechanical alloying [14]. Mechanical mixing by shearing during plastic deformation of powder particles is expected to occur when mixtures of as-received powders of ductile elements are ground while mixing due to welding of the particules should occur predominantly when the powders are premilled separately and then mechanically alloyed together. We have investigated the phase transformations of a $\mathrm{Fe}_{50} \mathrm{Cu}_{50}$ alloy during mechanical alloying of powder mixtures, with and without pre-milling, in order to characterise the influence of the mixing mode on the final stationary state. These two alloying processes were studied and compared at different milling speeds of a Fritsch P6 planetary ball-mill (200 and $300 \mathrm{rpm}$ ). Firstly, the classical method of mechanically alloying of as-received elemental $\mathrm{Fe}$ and $\mathrm{Cu}$ powder blends was used. Later on, as-received powders of $\mathrm{Fe}$ and $\mathrm{Cu}$ were milled separately and then mixed in the required proportions and milled again.

\section{Experimental details}

$\mathrm{Fe}_{50} \mathrm{Cu}_{50}$ alloys were synthesised by mechanical alloying of $\mathrm{Fe}$ and $\mathrm{Cu}$ powders with a nominal purity of $99 \%$ and an average particle size of $60 \mu \mathrm{m}$ and $150 \mu \mathrm{m}$, respectively. Milling was performed in a planetary ball mill (Pulverisette 6 from Fritsch) using hardened steel vial $(250 \mathrm{ml})$ and balls (15 balls with $20 \mathrm{~mm}$ diameter each). A ball-to-powder weight ratio of 20:1 was used. The disc rotation speeds were either 200 or $300 \mathrm{rpm}$. Milling was performed in an argon atmosphere to avoid air contamination. The powders were mechanically alloyed either in the as-received condition (also named hereafter "straight condition") or after premilling the elements separately at $550 \mathrm{rpm}$ and $150 \mathrm{rpm}$ in the case of $\mathrm{Fe}$ and $\mathrm{Cu}$ respectively. The tendency of $\mathrm{Cu}$ powder particles to agglomerate increases when the rotation speed increases. Thereby, two different batches were obtained. The Vickers hardness of the $\mathrm{Cu}$ and $\mathrm{Fe}$ powders, as-received and after milling, was measured with a $100 \mathrm{~g}$ load, in a Shimadzu equipment, on cold compacted samples. Average values of 193 and $250 \mathrm{HV}$ were obtained for milled $\mathrm{Cu}$ and Fe powders respectively, against 49 and 80 $\mathrm{HV}$ for the as-received powders. The as-mechanically alloyed powders were characterized by means of electron probe microanalysis (EPMA), X-ray diffraction (XRD), scanning electron microscopy (SEM) and Mössbauer spectroscopy (MS). The X-ray diffraction patterns were obtained using Co $\mathrm{K}_{\alpha}$ radiation $(\lambda=0.17889 \mathrm{~nm})$. The mean crystallite sizes and microstrains were 
obtained from the widths of X-ray diffraction peaks using the Williamson-Hall method [15].

Mössbauer spectra were recorded at room temperature in transmission geometry with a spectrometer operating in conventional constant acceleration mode. $\mathrm{A}{ }^{57} \mathrm{Co}$ source in Rh matrix with a strength of $\approx 10 \mathrm{mCi}$ was used. The spectra were analysed by the method of Le Caër [16], which extracts a hyperfine magnetic field distribution, $\mathrm{P}(\mathrm{B})$, from an experimental spectrum. Lorentzian line-shapes were employed in this procedure.

\section{Results and discussion}

The X-ray diffraction patterns of the two $\mathrm{Fe}_{50} \mathrm{Cu}_{50}$ sample batches milled at 200 and $300 \mathrm{rpm}$ as a function of milling time are shown in figures 1 and 2, respectively. In all cases, a broadening of the diffraction peaks of both $\mathrm{Cu}$ and $\mathrm{Fe}$ occurs gradually with increasing milling time. The intensities of the diffraction peaks of $\mathrm{Fe}$ decrease more rapidly than those of $\mathrm{Cu}$ do. The diffraction peaks of $\mathrm{Cu}$ are no more observed after different periods of time depending on the milling process.

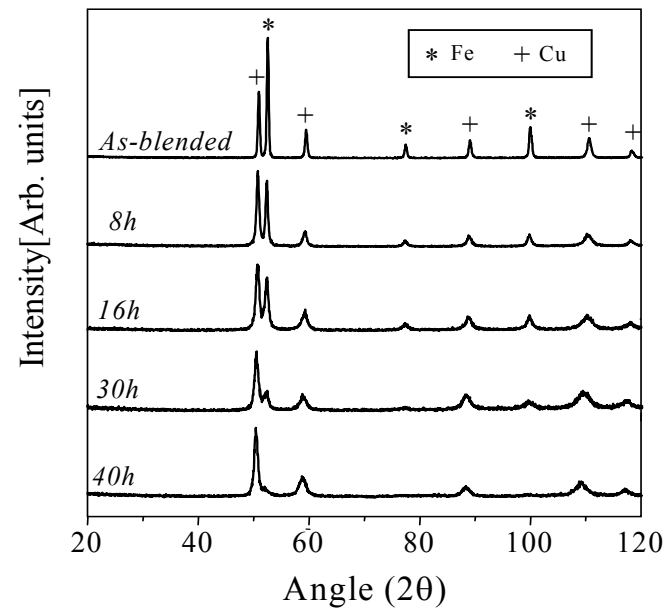

(a)

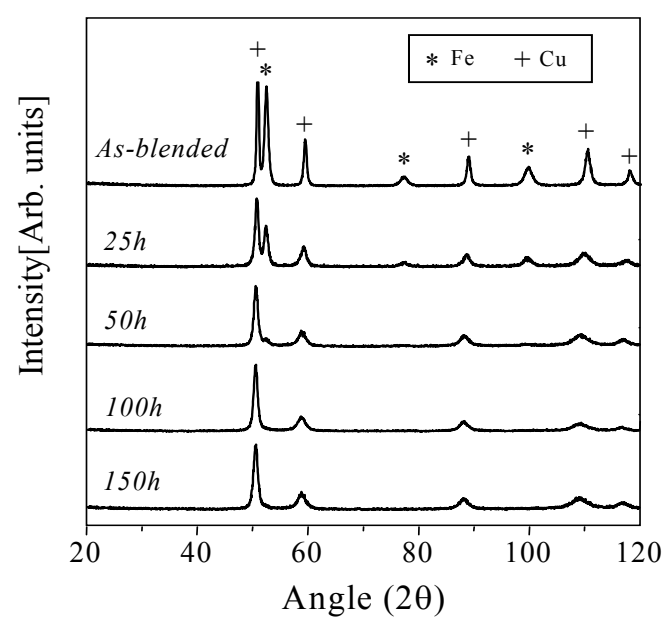

(b)

Figure 1 - XRD patterns of two $\mathrm{Fe}_{50} \mathrm{Cu}_{50}$ samples as a function of milling time (200 rpm) of: (a) starting mixtures of as-received powders, (b) starting mixtures of premilled powders.

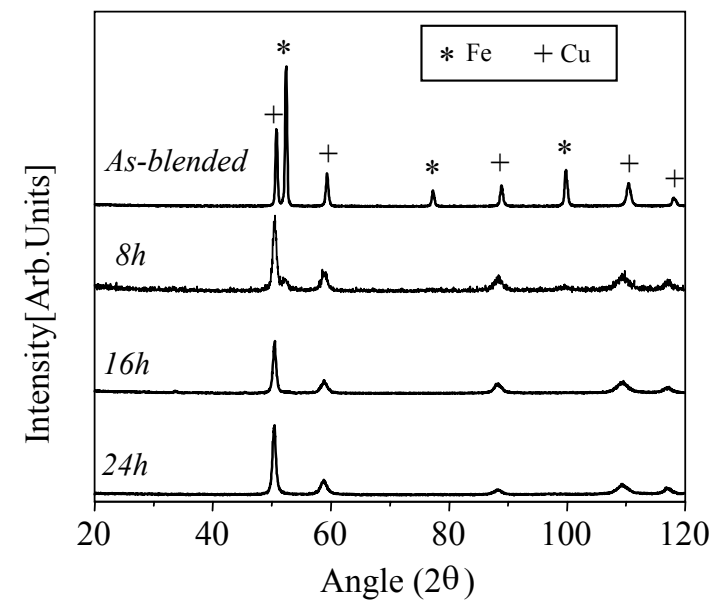

(a)

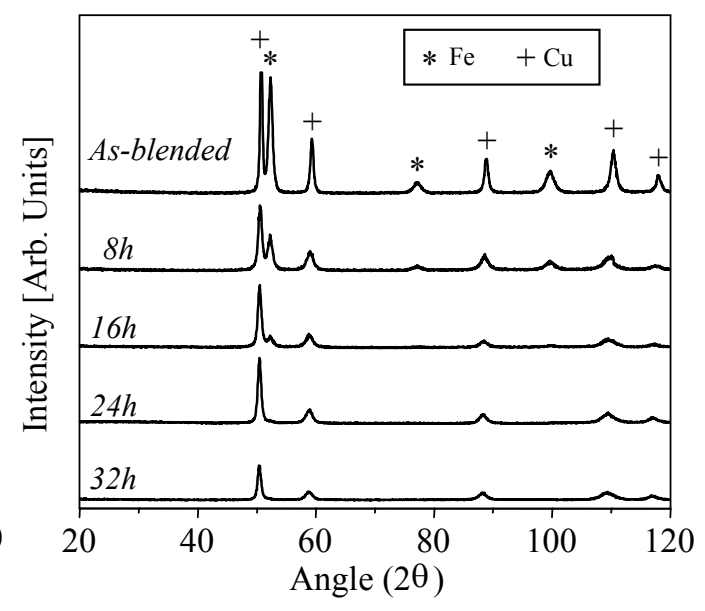

(b)

Figure 2 - XRD patterns of two $\mathrm{Fe}_{50} \mathrm{Cu}_{50}$ samples as a function of milling time (300 rpm) of : (a) starting mixtures of as-received powders, (b) starting mixtures of premilled powders. 
Starting from as-received powder mixtures, Figs. 1(a) and 2 (a), the X-ray peaks of Fe are no longer visible for milling times longer than $40 \mathrm{~h}$ and $8 \mathrm{~h}$, respectively. When initial blends are prepared from premilled powders, Figs. 1(b) and 2(b), vanishing of the Fe diffraction lines occurs for longer milling times, i.e longer than $50 \mathrm{~h}$ and $16 \mathrm{~h}$, respectively. In both processes, iron is incorporated in the fcc- $\mathrm{Cu}$ structure, giving rise to a fcc- $\mathrm{Cu}(\mathrm{Fe})$ solid solution whose diffraction peaks shift to higher angles with milling time as a consequence of a steadily increasing solubility of iron in copper. In equilibrium, the elements $\mathrm{Fe}$ and $\mathrm{Cu}$ are immiscible and the equilibrium $\mathrm{Fe}-\mathrm{Cu}$ phase diagram does not exhibit intermediate phases. The lattice parameters of the fcc- $\mathrm{Cu}(\mathrm{Fe})$ solid solutions obtained after the two milling processes (straight and premilled powders) are equal to $0.3638 \mathrm{~nm}$ for $200 \mathrm{rpm}$ and 0.3636 and $0.3635 \mathrm{~nm}$, for $300 \mathrm{rpm}$ and for straight and premilled processes respectively, which correspond to expanded fcc-Cu lattices $(\mathrm{a}=0.3615 \mathrm{~nm}$ for pure $\mathrm{Cu})$. In spite of the larger atomic size of copper when compared to iron, the fcc $\mathrm{Cu}$ lattice is expanded by the incorporation of iron atoms in agreement with previous works [2,4,12]. Harris et al [17] propose a model in which the strong interaction between like atom pairs ( $\mathrm{Fe}-\mathrm{Fe}, \mathrm{Cu}-\mathrm{Cu}$ ) provides Coulombic forces which establish geometrical limitations which prohibit the unlike $\mathrm{Fe}-\mathrm{Cu}$ pairs from coming any closer than the measured distances. In fact, the dilated bonds measured between $\mathrm{Cu}$ and $\mathrm{Fe}$ indicate that either a very weak interaction or a repulsion exists between unlike neighbours as a result of a positive heat of mixing in this system [16]. The crystallite sizes and microstrains in the stationary state of the milled powders, as determined by X-ray analysis are 9.5 $\mathrm{nm}$ and $0.4 \%$ (straight process) and $6.3 \mathrm{~nm}$ and $0.5 \%$ (premilled powders), respectively, for 200 $\mathrm{rpm}$ and $23 \mathrm{~nm}$ and $1.5 \%$ (straight process) and $13 \mathrm{~nm}$ and $1 \%$ (premilled powders), respectively, for $300 \mathrm{rpm}$. The crystallite size and microstrain measured in premilled Fe are $42 \mathrm{~nm}$ and $0.3 \%$, respectively, while the premilling of $\mathrm{Cu}$ reduces the crystallite size down to $52 \mathrm{~nm}$ with a microstrain of $0.2 \%$.

Figure 3 shows the standard-deviation $\sigma$. of the distribution of chemical composition, as estimated from EPMA measurements performed at 10 different points in each sample, as a function of milling time.

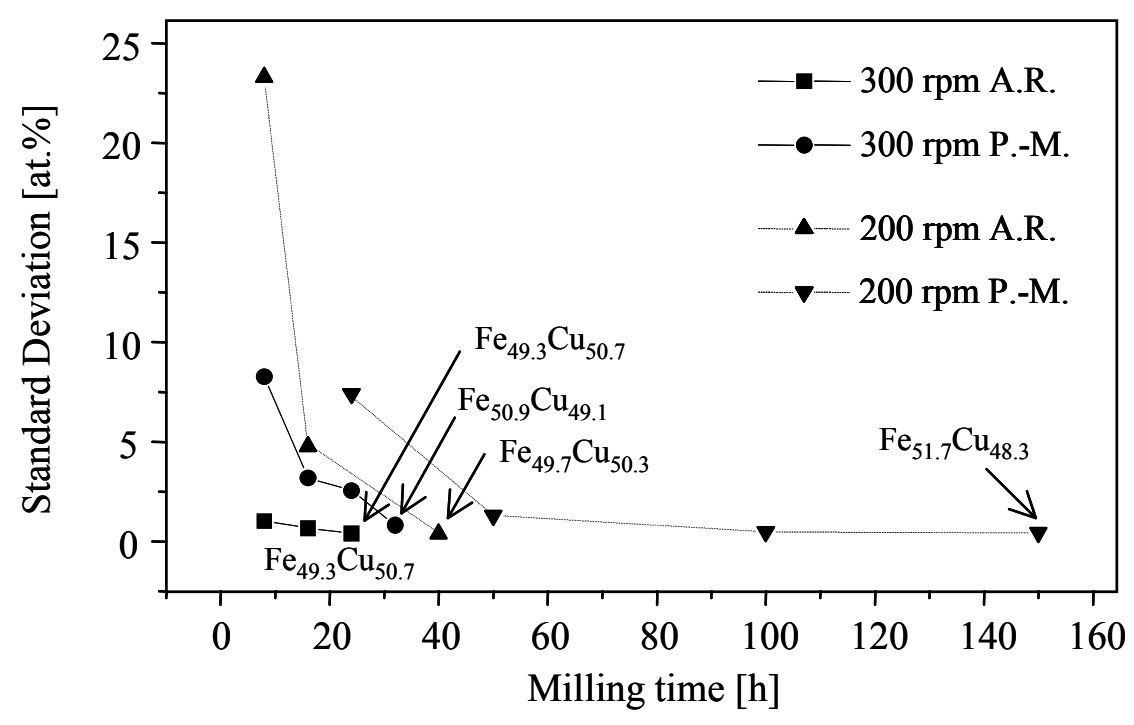

Figure 3 - Standard deviation of the distribution of chemical composition in particles of milled powders as a function of milling time and of milling conditions. A.R. = as-received powders; P-M. $=$ premilled powders. 
As expected, $\sigma$ decreases with milling time because the powder particles become gradually chemically homogeneous during mechanical alloying. The premilling process slows down the chemical homogenization for both 200 and $300 \mathrm{rpm}$ speeds, in agreement with the XRD results. Moreover, when the rotation speed is increased, the temperature and the injected specific power are increased. These phenomena speed up diffusion and lead, consequently, to an acceleration of the chemical homogenisation process and formation of a $\mathrm{Cu}(\mathrm{Fe})$ solid solution.

The final overall chemical composition of the samples is also presented in fig. 3. As can be seen, samples prepared from premilled powders are enriched in iron while the opposite is found for samples prepared from as-received powders. The sample obtained from premilled powders with a milling speed of $200 \mathrm{rpm}$ for $150 \mathrm{~h}$ is the one presenting the higher iron contamination. This means that the initial hardness of powders play an important role on their contamination during milling. In fact, the higher is the initial hardness, the more abrasive is the mixture and consequently the higher is the iron contamination. This phenomenon is increased by long-term milling processes.

Figures 4 and 5 show room-temperature Mössbauer spectra of two sample batches, i.e. (a) straight and (b) premilled, for different times of milling and for $200 \mathrm{rpm}$ and $300 \mathrm{rpm}$, respectively.

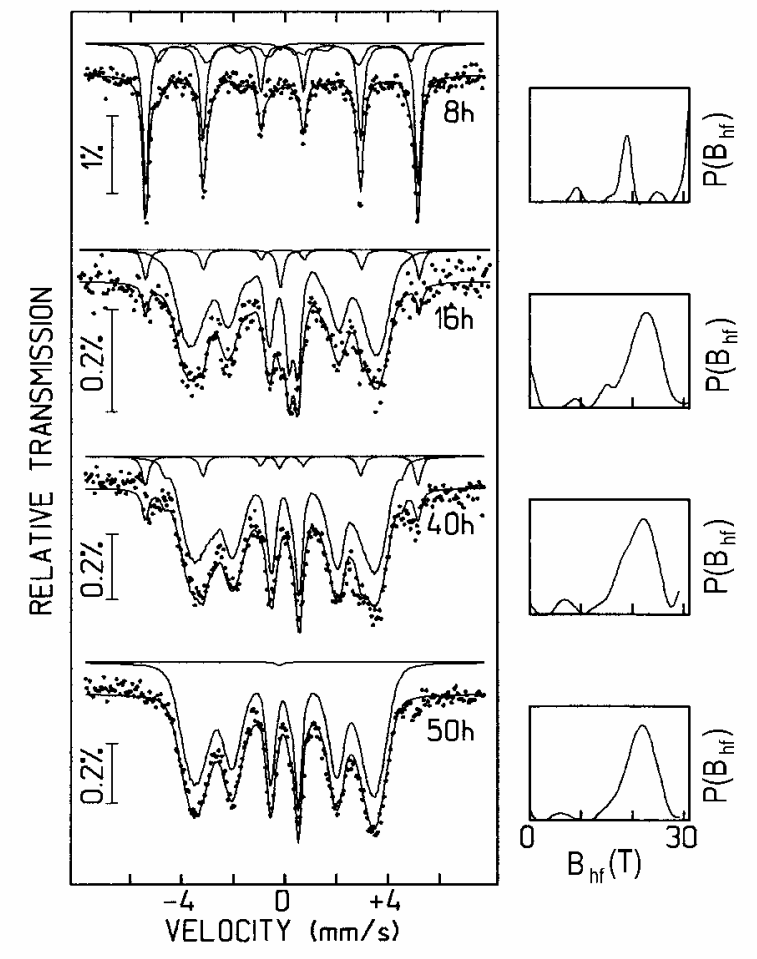

(a)

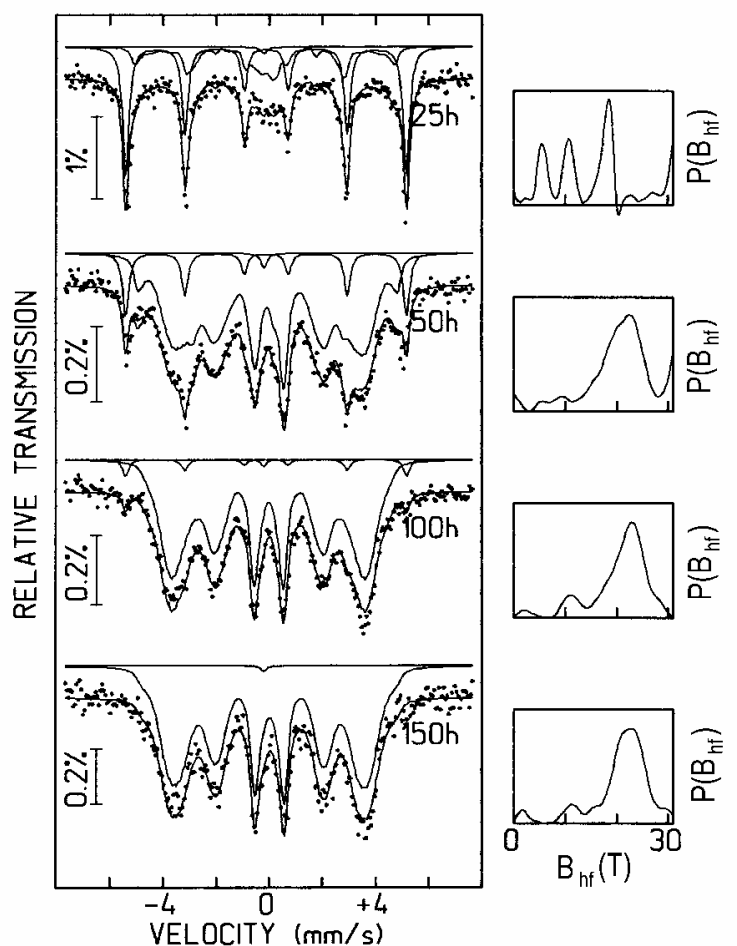

(b)

Figure 4 - Room temperature 57Fe Mössbauer spectra and the corresponding hyperfine magnetic field distributions for $\mathrm{Fe} 50 \mathrm{Cu} 50$ powders after different milling times $(200 \mathrm{rpm})$ of : (a) starting mixtures of as-received powders, (b) starting mixtures of powders of $\mathrm{Fe}$ and of $\mathrm{Cu}$ premilled separately.

Three different components can be distinguished. The first is a broadened sextet caused by the occurrence of a hyperfine magnetic field distribution which is attributed to the fcc-FeCu phase and is due to a broad distribution of environments of $\mathrm{Fe}$ atoms. The latter broad sextet demonstrates that $\mathrm{Fe}$ and $\mathrm{Cu}$ are alloyed at the atomic level but it does not necessarily imply that the corresponding 
alloy is compositionally homogeneous. The second is a sextet with a hyperfine field of $33 \mathrm{~T}$ characteristic of the bcc-Fe phase. It should be noted that the bcc-Fe phase was not detected by Xray diffraction for milling periods equal or longer than $40 \mathrm{~h}$ (straight process) or than $50 \mathrm{~h}$ (premilled powders) for $200 \mathrm{rpm}$ and longer than $16 \mathrm{~h}$ (straight process) or than $24 \mathrm{~h}$ (premilled powders) for $300 \mathrm{rpm}$. The latter sextet can be explained by the very small amount and the small crystallite size of the residual bcc-Fe phase which may at least partly come from a contamination by milling tools. The third transient contribution is a single line with an isomer shift of $-0.09 \mathrm{~mm} / \mathrm{s}$ characteristic of the fcc-Fe phase [19]. The latter phase was not detected by X-ray diffraction, likely for similar reasons. These observations are in agreement with a model proposed by Gente et al [20] and with results of Jiang et al [21] for samples obtained from powder mixtures of as-received elements. Similar results are obtained when starting from premilled powders.

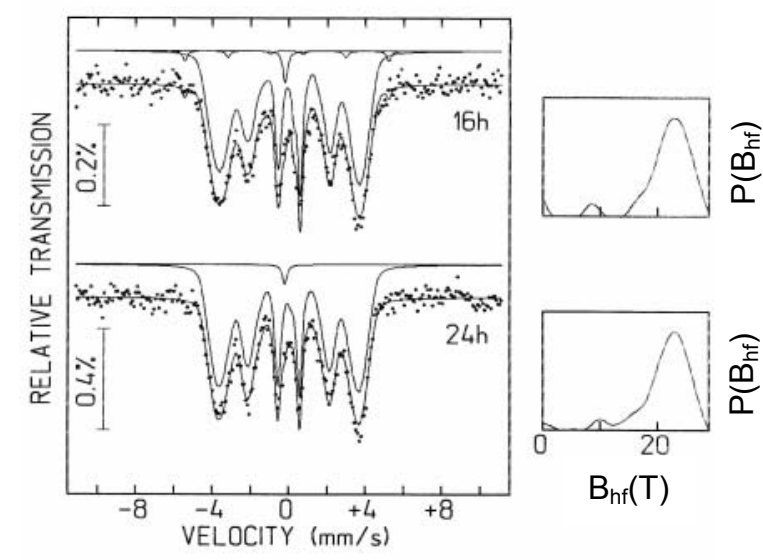

(a)

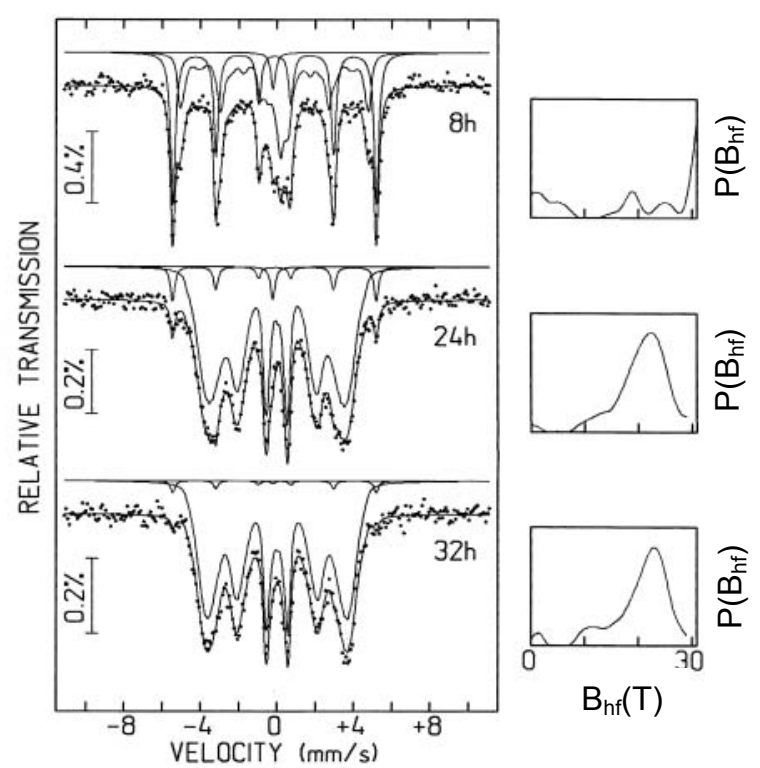

(b)

Figure 5 - Room temperature 57Fe Mössbauer spectra and the corresponding hyperfine magnetic field distributions for $\mathrm{Fe} 50 \mathrm{Cu} 50$ powders after different milling times $(300 \mathrm{rpm})$ of : (a) starting mixtures of as-received powders, (b) starting mixtures of powders of $\mathrm{Fe}$ and of $\mathrm{Cu}$ premilled separately.

Figures 6 and 7 show some SEM micrographs of particle morphologies as a function of milling time. As can be seen, in the final state the samples have a pellet shape of about $0.7 \mathrm{~mm}$ in diameter and about $0.3 \mathrm{~mm}$ in thick, independently of the milling process (Fig. 6 (a) and (b)). This reflects the fact that the fracture-welding equilibrium is shifted in the direction of welding, as a result of the high ductility of copper. This shape is obtained earlier in the straight milling process. Fig. 7 compares the morphologies of the particles milled for $1 \mathrm{~h}$ using the two milling processes. In the case of inverted back-scattered (BE) images, black and white zones correspond to copper and iron respectively. In the straight milling process, mixing is faster than in the second process, in which plates of iron and copper can be easily differentiated. Quantitative electron microprobe analysis confirms these observations. No significant compositional variations were observed in particles obtained from the straight process after $1 \mathrm{~h}$ of milling. By contrast, there are some compositional fluctuations in particles alloyed from premilled powders for $1 \mathrm{~h}$ (Fe- and $\mathrm{Cu}$-rich zones). Some iron particles were detected in the latter powders. The $\mathrm{Cu}$-rich particles are actually $\mathrm{Cu}(\mathrm{Fe})$ solid 
solutions with a significant iron amount. This means that, in contrast to the bcc-Fe structure, there is an incorporation of iron in the fcc-Cu structure from the beginning of the milling process.

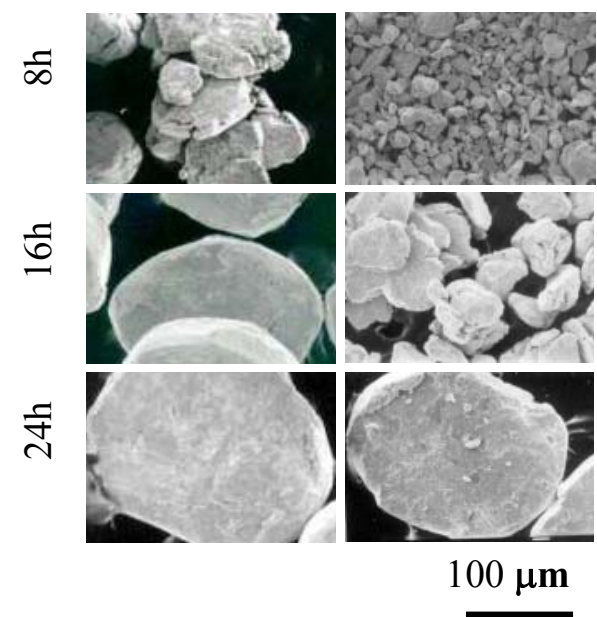

(a) (b)

Figure 6 - SEM particle morphologies $(70 x)$ as a function of milling time $(300$ rpm) : (a) initial mixture of as-received powders, (b) initial mixture of powders of $\mathrm{Fe}$ and of $\mathrm{Cu}$ premilled separately.

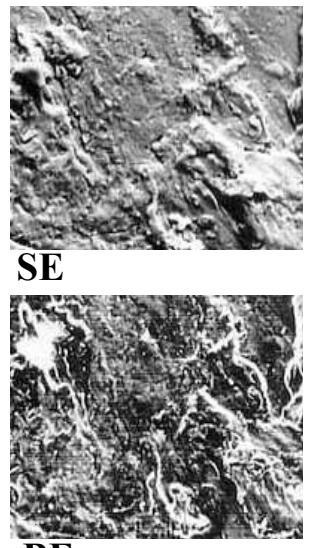

BE

(a)

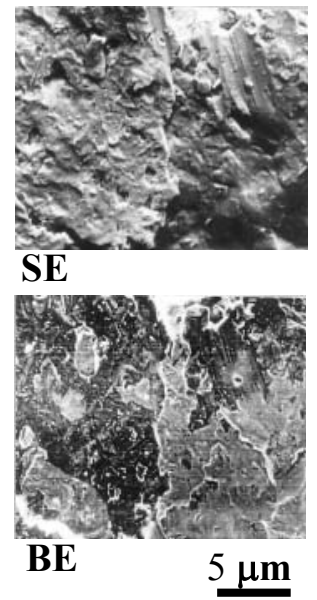

(b)

Figure 7 - SEM images (1500x) of powder particles as a function of milling time. (a) initial mixture of as-received powders, (b) initial mixture of powders of $\mathrm{Fe}$ and of $\mathrm{Cu}$ premilled separately. $\mathrm{SE}=$ secondary electrons, $\mathrm{BE}=$ back-scattered electrons. (300rpm).

\section{Conclusions}

The XRD and MS results show that it is possible to incorporate iron in the fcc-Cu matrix by the two milling processes used in this work. In both procedures, a broad distribution of different local environments of iron atoms was observed in the Mössbauer spectra of the fcc-FeCu phase. Mössbauer spectra show further that a fcc non magnetic Fe-rich phase is formed transiently. The reactions are slowed down when premilled powders are used as starting materials. In our milling conditions, similar fcc solid solutions are formed for $50 \mathrm{~h}$ (straight condition) and $150 \mathrm{~h}$ (premilled powders) when $200 \mathrm{rpm}$ are used, and for $24 \mathrm{~h}$ (straight condition) and 32h (premilled powders) when $300 \mathrm{rpm}$ are used. As expected, it was observed that at $300 \mathrm{rpm}$ the alloying process occurs faster than at $200 \mathrm{rpm}$, both in the straight and premilled conditions.

\section{Acknowledgements}

This work was partly funded by the Portuguese-French ICCT-Ambassade de France à Lisbonne cooperation. The authors also thank Pierre Delcroix (LSG2M) for useful suggestions.

\section{References}

[1] C.L. Chien, J.Q. Xiao and J.S. Jiang, J. Appl. Phys. 73 (1993), p. 5309.

[2] L. B. Hong and B. Fultz, Acta mater. 46 (1998) 2937.

[3] J.Z. Jiang, C. Gente and R. Bormann, Mater. Sci. Eng. A 242 (1998), p. 268. 
[4] P. Crespo and A. Hernando, Recent Res. Devel. Nanostructures, 1 (1999), p. 63.

[5] N. Wanderka, U. Czubayko, V. Naundorf, V.A. Ivchenko, A. Ye. Yermakov, M.A. Uimin and H. Wollenberger, Ultramicroscopy 89 (2001), p. 189.

[6] M.B. Fernandez van Raap, L.M. Socolovsky, F.H. Sanchez and I.L. Torriani, J. Phys. Condens. Matter 14 (2002), p. 857.

[7] J. Xu, G.S. Collins, L.S.J. Peng and M. Atzmon, Acta mater. 47 (1999), p. 1241.

[8] P.J. Schilling, J.H. He, R.C. Tittsworth and E. Ma, Acta mater. 47 (1999), p. 2525.

[9] S.D. Kaloshkin, I.A. Tomilin, G.A. Andrianov, U.V. Baldokhin, E.V. Shelekhov, Mater. Sci. Forum 235-238 (1997), p. 565.

[10] J.H. He, H.W. Sheng, J.S. Lin, P.J. Schilling, R.C. Tittsworth and E. Ma, Phys. Rev. Lett. 89 (2002), p. 125507.

[11] P. Delcroix, T. Ziller, C. Bellouard, G. Le Caër, Mater. Sci. Forum 360-362 (2001), p. 329.

[12] J.Y. Huang, J. Mater. Sci., 31 (1996), p. 4165.

[13] D. Choulier, R. Rahouadj and E. Gaffet, Ann. Chim. Sci. Mat. 22 (1997), p.351.

[14] E. Zhou, C. Suryanarayana and F.H. Froes, Mater. Lett. 23 (1995), p. 27.

[15] G. Williamson and W.H. Hall, Acta Metall. 1 (1952), p.22.

[16] G. Le Caër and J.M. Dubois, J. Phys. E 12 (1979), p. 1083.

[17] V.G. Harris, K.M. Kemner, B.N. Das, N.C. Koon, A.E. Ehrlich, J.P. Kirkland, J.C. Woicik, P. Crespo, H. Hernando, A. Garcia Escorial, Phys. Rev. B 54 (1996), p. 6929.

[18] E. Ma, H.W. Sheng, J.H. He and P.J. Schilling, Mater. Sci. Eng. A 286 (2000), p. 48.

[19] R. Halbauer and U. Gonser, J. Magn. Magn. Mater. 35 (1983), p. 55.

[20] C. Gente, M. Oehring and R. Borman, Phys Rev B 48 (1993), p.13244.

[21] J.Z. Jiang, U. Gonser, C. Gente and R. Borman, Appl. Phys. Lett. vol 63, no.20 (1993), p. 2768 . 